\title{
Jenis-Jenis Tumbuhan Suku Fabaceae, Subfamili Caesalpinioideae Di Areal Kampus Universitas Tadulako, Palu
}

\section{Species Diversity of Fabaceae, Subfamily Caesalpinioideae In The Campus Area of Tadulako University, Palu}

\author{
Rahmita $^{1^{*}}$, Ramadanil ${ }^{1}$, Moh. Iqbal ${ }^{1^{*}}$ \\ 1 Jurusan Biologi, Fakultas MIPA Universitas Tadulako Jl. Soekarno Hatta km 9 Tondo, Palu 94117, Sulawesi Tengah, \\ Indonesia.
}

Keywords: Fabaceae, description, invasive, Tadulako University.

Keywords: Fabaceae, deskripsi, invasif, Universitas Tadulako.

${ }^{*}$ Coresponding Author: rahmita.hasmin@gmail.com iqbalmoh89@gmail.com

\begin{abstract}
Research on the species of Plants of the Fabaceae Tribe Subfamili Caesalpinioideae at the area of Tadulako University Campus has been conducted from January to April 2019. This study aims to record, describe and determine the invasive status of plant species Fabaceae subfamili Caesalpinioideae. The research was based on botanical exploration method. The results showed there were 10 species from subfamily Caesalpinioideae including Acacia farnesiana (L.) Willd., Albizia saman (Jacq.) Merr., Caesalpinia pulcherrima (L.) Sw., Cassia javanica L., Delonix regia (Hook.) Raf., Desmanthus virgatus (L.) Willd., Leucaena leucocephala (Lam.) de Wit, Mimosa pigra L., Mimosa pudica L., Senna siamea (Lam.) H.S.Irwin \& Barneby. Number of Species have been used as protective plants (5 species), as ornamental plants (2 species) and potentially as invasive species (3 species).
\end{abstract}

\begin{abstract}
Abstrak
Penelitian Jenis-Jenis Tumbuhan Suku Fabaceae Subfamili Caesalpinioideae di Areal Kampus Universitas Tadulako telah dilaksanakan pada bulan Januari hingga April 2019. Penelitian ini bertujuan mendata, mendeskripsi dan menentukan status invasif jenis-jenis tumbuhan Fabaceae subfamili Caesalpinioideae. Penelitian menerapkan metode eksplorasi botani yaitu dengan cara menulusuri areal kampus UNTAD. Hasil penelitian didapatkan 10 spesies dari subfamili Caesalpinioideae meliputi jenis Acacia farnesiana (L.) Willd., Albizia saman (Jacq.) Merr., Caesalpinia pulcherrima (L.) Sw., Cassia javanica L., Delonix regia (Hook.) Raf., Desmanthus virgatus (L.) Willd., Leucaena leucocephala (Lam.) de Wit, Mimosa pigra L., Mimosa pudica L., Senna siamea (Lam.) H.S.Irwin \& Barneby. Jenis-jenis yang telah dimanfaatkan untuk tanaman pelindung (5 jenis), tanaman hias (2 jenis) serta jenis yang berpotensi invasif ( 3 jenis).
\end{abstract}

\section{Latar Belakang}

Fabaceae tergolong dalam famili tumbuhan berbunga terbesar ketiga setelah Compositae dan Orchidaceae (LPWG, 2017), terdiri atas 770 genus dan lebih dari 19.500 jenis (Lewis, 2005). Beberapa ahli botani mengelompokkan jenis-jenis Fabaceae kedalam 6 subfamili yaitu Duparquetioideae (1 genus, 1 jenis),
Cercidoideae (12 genus, lebih dari 335 jenis), Detarioideae (84 genus, ca. 760 jenis), Dialioideae (17 genus, ca. 85 jenis), Caesalpinioideae (148 genus, ca. 4400 jenis) dan Papilionoideae (503 genus, ca. 14.000 jenis) (LPWG, 2017). Dari ke 6 subfamili Fabaceae yang dilaporkan oleh LPWG (2017), 5 subfamili memiliki persebaran di kawasan Malesiana dan satu 
subfamili yaitu Duparquetioideae berstatus endemik Afrika Tengah dan Afrika Barat dan belum dilaporkan persebarannya di Kawasan Malesiana.

Fabaceae umumnya dikenal dari tipe buah Legum atau polong-polongan dan terdiri dari berbagai bentuk perawakan seperti pohon, perdu, semak dan herba. Daun terletak berseling atau berhadapan, bertipe majemuk, uni atau bifoliate (Cercidoideae, Papilionideae, umumnya Caesalpinioideae, kadang Detarioideae), paripinnate (Detarioideae), imparipinate (Dialioideae), umumnya berdaun penumpu atau berupa duri.

Tumbuhan Fabaceae berbunga bisexual atau kadang unisexual, bersimetris aktinomorfik atau zigomorfik dan tipe bunga papilionate (Papilionideae) atau bukan papilionate (Duparquetioideae, umumnya Caesalpinioideae, Cercidoideae, Detarioideae, Dialioideae). Kelopak berlekatan atau saling berlepasan berjumlah 5 (3-6). Petal (0-)5(atau 6) atau mahkota bertipe papilionaceous yaitu kelopak berukuran besar di bagian posterior (bendera), dua kelopak lateral (sayap) dan dua kelopak dibagian bawah (lunas). Buah umumnya bertipe polong, beberapa buah bersayap, buah batu (Simpson, 2010; LPWG, 2017).

Beberapa tahun terakhir, kampus Universitas Tadulako melakukan pembangunan yang cukup pesat, hal ini berdampak berkurang hingga hilangnya jenis tumbuhan di lingkungan Kampus. Selain itu, ancaman terhadap keanekaragaman hayati tidak hanya disebabkan oleh eksploitasi yang berlebihan terhadap sumber daya alam atau alih fungsi lahan, tetapi juga disebabkan oleh adanya spesies tumbuhan invasif. Spesies tumbuhan invasif mampu menekan pertumbuhan spesies tumbuhan asli yang terdapat di dalam ekosistem sehingga dapat mengakibatkan kepunahan lokal terhadap spesies tumbuhan asli. Oleh karena itu, inventarisasi jenis-jenis Fabaceae subfamili Caesalpinioideae di lingkungan Kampus Universitas Tadulako dianggap penting untuk didata dan diinformasikan kembali.

\section{Bahan dan Metode}

Eksplorasi jenis-jenis Fabaceae subfamili Caesalpinioideae di Areal Kampus Universitas Tadulako telah dilaksanakan pada bulan Januari hingga April 2019. Pengambilan sampel dilakukan dengan metode eksplorasi (Rugayah dkk., 2004) yaitu menjelajahi seluruh wilayah Kampus terutama di area terbuka hijau hingga taman dimasing-masing Fakultas dan di lingkungan bangunan sarana prasarana lainnya (Gambar 1).

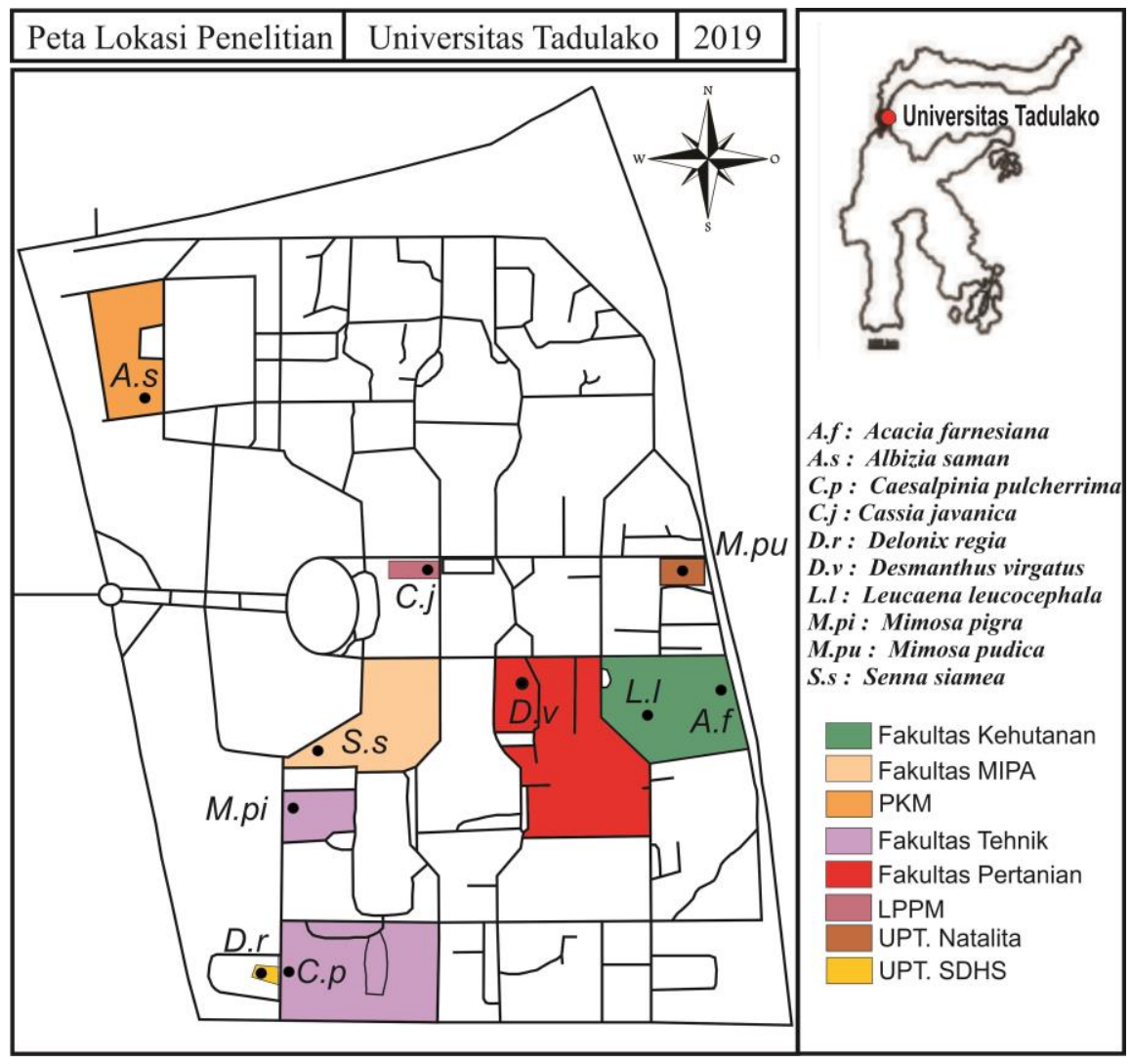

Gambar 1. Peta lokasi penelitian dan koleksi sampel 
Sampel koleksi tumbuhan Fabaceae subfamili Caesalpinioideae yang ditemukan di lapangan diambil bagian ranting berdaun, berbunga atau berbuah, kemudian diberi label gantung yang telah diberi nomor koleksi. Tiap koleksi tumbuhan dilakukan pencatatan informasi penting seperti koordinat, kondisi habitat, manfaat, status tumbuhan (liar atau ditanam) dan karakter morfologi penting yang mudah hilang ketika dilakukan proses herbarium seperti warna dan bentuk. Bersamaan dengan itu juga dilakukan pengambilan dokumentasi tiap koleksi tumbuhan.

Koleksi tumbuhan hasil eksplorasi kemudian dilakukan proses pengeringan menggunakan oven listrik pada suhu $600-700 \mathrm{C}$ hingga sampel kering sempurna. Sampel yang telah kering kemudian dilakukan identifikasi menggunakan buku identifikasi seperti, van Steenis, 2006; Hou et al., 1996; Nielsen et al.. 1992; Backer and van Den Brink, 1963.

Identifikasi jenis tumbuhan invasif dilakukan pengamatan langsung di lapangan dan mengacu pada buku panduan seperti Webber (2003), ISSG (2005).

\section{Hasil dan Pembahasan}

Hasil eksplorasi Fabaceae subfamili Caesalpinioideae di Kampus Universitas Tadulako ditemukan 10 jenis meliputi Acacia farnesiana (L.) Willd., Albizia saman (Jack.) Merr., Caesalpinia pulcherrima (L.) Sw, Cassia javanica L., Delonix regia (Hook.) Raf, Desmanthus virgatus (L.) Willd., Leucaena leucocephala (Lam.) de Wit., Mimosa pigra L., Mimosa pudica L., dan Senna siamea (Lam.) H.S. Irwin \& Barneby. Keanekaragaman jenis dan lokasi tumbuh serta status tumbuhan yang ditemukan di lokasi, disajikan pada Tabel 1.

Famili Fabaceae merupakan salah satu famili yang bernilai ekonomi tinggi. Banyak anggotanya yang telah dibudidayakan sebagai tanaman pangan penghasil buah seperti Tamarindus indica L., tanaman hias Bauhinia variegata L., karena mempunyai bunga dan daun yang unik yaitu daunnya bercuping dua dan simetri, berbentuk seperti kupukupu dan bunganya yang indah, jenis yang lain seperti Caesalpinia pulcherrima (L.) Sw memiliki mahkota bunga warna merah dan kuning menyala menambah nilai estetika suatu taman (Ariati dkk., 2001). Ditemukan tanaman yang ditanam sebagai peneduh jalan (sebanyak 5 jenis) di Kampus Universitas Tadulako yaitu $S$. siamea, $D$. regia, $A$. saman, $L$. leucocephala, G. sepium. dan ditanam sebagai tanaman hias (2 jenis) yaitu C. pulcherrima, A. saman (Tabel 1).

Jenis-jenis Fabaceae dari subfamili Caesalpinioideae yang ditemukan di Kampus Universitas Tadulako memiliki perawakan Pohon dan semak. Tipe perawakan pohon meliputi $A$. farnesiana (L.) Willd., $A$. saman (Jack.) Merr., C. pulcherrima (L.) Sw, C. javanica L., D. regia (Hook.) Raf, L. leucocephala (Lam.) de Wit., dan S. siamea (Lam.) H. S. Irwin \& Barneby. Semak meliputi $D$. virgatus (L.) Willd., $M$. pigra L., dan M. pudica L. (Gambar 2).

Dari semua jenis yang didapatkan ada yang tumbuh secara liar dan ada juga yang sengaja ditanam sebagai tanaman budidaya. Beberapa yang ditemukan berstatus sebagai tanaman liar diantaranya $A$. farnesiana (L.) Willd., D. virgatus (L.) Willd., M. pigra L., dan $M$. pudica $L$. Jenis yang ditemukan berstatus sebagai tanaman budidaya diantaranya $A$. saman (Jack.) Merr., C. pulcherrima (L.) Sw, C. javanica L., D. regia (Hook.) Raf, L. leucocephala (Lam.) de Wit., dan S. siamea (Lam.) H.S.Irwin \& Barneby.

Berdasarkan pengamatan lapangan, ada beberapa jenis yang ditemukan dan teridentifikasi sebagai tumbuhan invasif diantaranya $A$. farnesiana (L.) Willd yang berperawakan pohon diketahui berasal dari Amerika tropis dan sekarang diperkenalkan ke semua daerah tropis dan sub tropis, hingga tercatat di seluruh malesia (Nielsen, 1992). M. pudica L., M. pigra L. diketahui berasal dari wilayah tropis Amerika Selatan dan diintroduksi ke beberapa negara sebagai tanaman hias, namun menginvasi secara luas ekosistem di Afrika, Asia Tenggara dan Australia (ISSG, 2005).

\section{Kunci identifikasi Jenis Subfamili Caesalpinioideae Caesalpinioideae}

Caesalpinioideae DC., Prodr. 2:473. 1825

Pohon, semak, liana, biasanya terdapat duri atau tidak. Daun penumpu di samping pangkal daun, dan berlepasan atau tidak ada. Daun biasanya pulvinate, bipinnate, jarang imparipinnate. Perbungaan globosa, spicate, paniculate, racemose; bracteola ada atau kecil. Bunga biseksual atau uniseksual, atau biseksual dengan uniseksual dan atau dalam heteromorfik, sering simetris bilateral atau asimmetric; sepal (3-)5(6), berlepasan atau menyatu; petal (3-)5(-6), berlepasan atau menyatu, aestivation valvate atau imbricate; stamen 4 atau 5, biasanya banyak, berlepasan atau berlekatan. Buah 1 sampai banyak. 
Tabel 1. Keanekaragaman jenis-jenis Tumbuhan Subfamili Caesalpinioideae di Areal Kampus Universitas Tadulako.

\begin{tabular}{|c|c|c|c|c|}
\hline No & Nama Species & Koordinat & Alt (mdpl) & Status \\
\hline 1 & Acacia farnesiana (L.) Willd. & S $0^{\circ} 51^{\prime} 31,6^{\prime \prime} ; \quad$ E $119^{0} 54^{\prime} 01,4^{\prime \prime}$ & 106 & Liar \\
\hline 2 & Albizia saman (Jacq.) Merr. & S $0^{\circ} 49^{\prime} 98,4^{\prime \prime} ;$ E $119^{0} 53^{\prime} 40,5^{\prime \prime}$ & 45 & Ditanam \\
\hline 3 & Caesalpinia pulcherrima (L.) Sw. & S $0^{0} 50^{\prime} 55,6^{\prime \prime} ;$ E $119^{0} 53^{\prime} 54,7^{\prime \prime}$ & 67 & Ditanam \\
\hline 4 & Cassia javanica L. & S $0^{\circ} 50^{\prime} 14,4^{\prime \prime} ;$ E $119^{0} 53^{\prime} 68,2^{\prime \prime}$ & 74 & Ditanam \\
\hline 5 & Delonix regia (Hook.) Raf. & S $0^{0} 50^{\prime} 56,7^{\prime \prime} ;$ E $119^{0} 53^{\prime} 51,7^{\prime \prime}$ & 60 & Ditanam \\
\hline 6 & Desmanthus virgatus (L.) Willd. & S $0^{\circ} 50^{\prime} 25,8^{\prime \prime} ;$ E $119^{0} 53^{\prime} 73,8^{\prime \prime}$ & 78 & Liar \\
\hline 7 & Leucaena leucocephala (Lam.) de Wit & S $0^{\circ} 50^{\prime} 26,4^{\prime \prime} ;$ E $119^{0} 53^{\prime} 94,1^{\prime \prime}$ & 101 & Ditanam \\
\hline 8 & Mimosa pigra $\mathrm{L}$ & S $0^{\circ} 50^{\prime} 37,1^{\prime \prime} ;$ E $119^{\circ} 53^{\prime} 54,6^{\prime \prime}$ & 57 & Liar \\
\hline 9 & Mimosa pudica L. & S $0^{0} 50^{\prime} 16,4^{\prime \prime} ;$ E $119^{0} 53^{\prime} 95,5^{\prime \prime}$ & 104 & Liar \\
\hline 10 & Senna siamea (Lam.) H.S.Irwin \& Barneby & $S 0^{\circ} 50^{\prime} 37,7^{\prime \prime} ; \quad$ E $119^{\circ} 54^{\prime} 0,6^{\prime \prime}$ & 105 & Ditanam \\
\hline
\end{tabular}

1 a. Bunga bongkol. Semak, pohon 2

b. Bunga aktinomorfik. Pohon

2 a. Semak merambat; batang berduri, ujung bengkok. Daun bipinnate; sirip 1 atau 2 pasang; anak daun 12-26 pasang.......... Mimosa pudica

b. Semak, Pohon .................................. 3

3 a. Semak ........................................ 4

b. Pohon ...................................... 5

4 a. Semak tinggi $2 \mathrm{~m}$......... Desmanthus virgatus

b. Semak tinggi $1 \mathrm{~m} \mathrm{...................Mimosa} \mathrm{pigra}$

5 a.Pohon; perbungaan 1 atau 2

\section{Leucana leucocephala}

b. Pohon; perbungaan 1-3 ......Acacia farnesiana

6 a. Daun menyirip genap ........................ 7

b. Daun Majemuk menyirip genap ............... 8

7 a. Benang sari 10, fertile 7, staminodia 3. Sepal 5, bundar telur, kuning terang ....... Senna siamea

b. Benang sari 10. Sepal 5, putihpink ............................. Cassia javanica

8 a. Petal 5, 1 petal lebih kecil

\section{Caesalpinia pulcherrima}

b. petal 5, 1 petal lebih besar dari petal yang lainnya Delonix regia

Acacia farnesiana (L.) Willd.

Pohon, tinggi 1-3 m; kulit kayu cokelat, keras; percabangan banyak, terdapat lentisel. Daun majemuk ganda, berseling, 4,5-8 cm; sirip berhadapan, 4-9 pasang sirip; tangkai daun $1 \mathrm{~cm}$; anak daun 10-22 pasang, berhadapan, memanjang-jorong, ujung bulat, pangkal miring atau tidak simetris, 2-6 mm x 1-2 mm; tangkai daun pendek; berduri $1-2 \mathrm{~cm}$. Perbungaan malai, terletak diujung atau diketiak daun, bongkol 1-3, bongkol berdiameter $1,5 \mathrm{~cm}$, kuning; tangkai panjang 3 $\mathrm{cm}$, berambut. Bunga kecil, kuning, beraroma; Kelopak berbentuk tabung, panjang ca. $1 \mathrm{~mm}$; Mahkota bertaju 5 , berbentuk tabung, panjang ca. $1 \mathrm{~mm}$; Stamen banyak, kecil, $4 \mathrm{~mm}$, kuning, tangkai sari berlepasan.
Putik berbentuk jarum; kepala putik capitate. Buah polong, pipih, agak lurus atau membengkok $3-11 \mathrm{~cm} \mathrm{x}$ $1,5-1 \mathrm{~cm}$, berambut. Biji hingga 10 .

\section{Caesalpinia pulcherrima (L.) Sw.}

Pohon, perdu; tinggi 2-4 m. ranting berduri. Daun penumpu berbentuk jarum, mudah luruh. Daun bipinnate, berseling atau tersebar; sirip 5-9 pasang, 20$30 \mathrm{~cm}$; anak daun behadapan, 6-12 persirip, tangkai daun pendek, melonjong-elips, ujung membundarterbelah, pangkal tidak simetris, menumpulmembundar, pinggiran rata, permukaan atas hijau terang, permukaan bawah hijau pucat, 9-30x 5-15 mm. Perbungaan di ketiak dan diujung, tandan, panjang 20$50 \mathrm{~cm}$. Bunga zigomorfik, berkelamin 2; sepal bertaju 4-5, 10-15 x 5-7 mm. petal kuning atau merah terang, 10-25 x 6-8 mm. Benang sari 10, berlepasan, 5,5-7,5 $\mathrm{cm}$; tangkai sari dibagian bawah berambut; anthers 1-2 $\mathrm{mm}$ panjang. Buah polong, pipih, 6-12 x 1-2 cm. Biji bundar telur-persegi, cokelat, 8-10 x 6-8 mm.

\section{Delonix regia (Hook.) Raf.}

Pohon, tinggi 10-20 m; kulit batang abu-abu cokelat, mengelupas, kasar. Daun menyirip ganda, sirip 9-21, membesar dibagian tengah; anak daun berhadapan, per sirip 10-28 pasang, melonjong-oval, dasar membulat, ujung tumpul, pinggiran rata, $2-5 \times 0,5 \mathrm{~cm}$; tangkai daun 8-10 $\mathrm{cm}$. Perbungaan malai terletak di ujung atau di ketiak daun, $20-25 \mathrm{~cm}$; bunga berseling, 6-12; anak tangkai bunga, 3-7 cm; daun penumpu meruncing, 0,5-0,8 mm; Sepal 5, jorong, ujung acute, 2-2,5 cm; mengatup. Petal berlepasan, 5, meyudip, 5-7 $x$ 3,7-5 cm, merah terang, 1 daun kelopak bagian atas bercorak putih dan kuning, bagian bawah merah terang. Benang sari 10, berlepasan, merah, pangkal tangkai sari berambut; tangkai sari $3-4,5 \mathrm{~cm}$; kepala sari 2. Putik 1, panjang $5 \mathrm{~cm}$. Buah polong, melonjong, keras, $15-38 \mathrm{~cm} \times 3-6 \mathrm{~cm}$, cokelat. Biji melonjong. 


\section{Leucaena leucocephala (Lam.) de Wit}

Semak atau pohon kecil, tinggi 2-5 m. Percabangan berbulu halus, halus ketika tua, terdapat lentisel. Daun bipinnate, berseling; pinnae 4-8 pasang, 5-9 cm, tangkai daun halus dengan kelenjar; anak daun berhadapan, 5-15 pasang, linear-jorong, 7-13 x 1.5-3 $\mathrm{mm}$, pangkal membulat atau tidak simetris, ujung meruncing; daun penumpu mudah luruh, linear, kecil Perbungaan biasalnya 1 atau 2, terletak di ketiak daun, 2-3 cm diameter; tangkai bunga $2-4 \mathrm{~cm}$; bract mudah luruh, berambut halus. Bunga putih; calyx $3 \mathrm{~mm}$, berambut halus di bagian ujung, 5 taju. Petal lanset terbalik, ca $5 \mathrm{~mm}$. Stamen banyak, $10 \mathrm{~mm}$, berambut halus; Stigma copular. Buah polong panjang, tipis, $10-20 \times 1-2 \mathrm{~cm}$. Biji 6-25, cokelat, agak bulat telur, tipis, $6-9 \times 2-4.5 \mathrm{~mm}$.

\section{Senna siamea (Lamarck) H. S. Irwin \& Barneby}

Pohon, tinggi 5-20 m. Kulit kayu agak keras, permukaan kasar, abu-abu. Daun penumpu kecil, mudah luruh. Daun menyirip genap, tersusun spiral, daun menyirip genap; anak daun berhadapan, 6-12 pasang, melonjong, pangkal membulat, ujung membulat atau terbelah, pinggiran rata, bagian atas hijau mengkilap, bawah agak pucat, $3-5 \times 1-2 \mathrm{~cm}$. Perbungaan tandan, terletak di ujung ranting daun, panjang $15-25 \mathrm{~cm}$. Sepal 5, lanset, 5-7 mm, hijau terang. Petal 5, berlepasan, bundar telur, $1-1.5 \mathrm{~cm}$ x 8-mm, kuning cerah. Benang sari 10; fertile 7, tangkai sari ca. $8 \mathrm{~mm}$, hijau; staminodia 3 , tangkai sari ca. mm. kepala sari terbelah 2, kaku, cokelat, 3-5 mm. Putik 1, 1-1.5 cm. Buah polong, kaku, $10-25 \mathrm{~cm} \times 1-1.5 \mathrm{~cm}$. Biji 10-30, pipih, cokelat terang.

\section{Cassia javanica L.}

Pohon, tinggi $20 \mathrm{~m}$. Daun penumpu di ketiak, panjang berlekuk, hijau muda. Daun berseling atau spiral, paripinnate, $15-40 \mathrm{~cm}$; anak daun 6-26 psang, bulat telur, $2-8 \times 1.2 \times 1.5-3 \mathrm{~cm}$, perbukaan berbulu, dasar astmetiric, ujung acute, obtuse atau sedikit acuminate. Perbungaan lateral atau di ujung ranting daun, 2-banyak bunga. Sepal ovate atau broadly lanceolate, hijau, panjang 5-10 $\mathrm{mm}$; petals 5, kuning-pink, 2.5-4.5 $\times 1-2 \mathrm{~cm}$. stamen 10, berlepasan, 3 bertangkai pendek. Ovary berlambut halus. Buah polong, terete, keras, $30-50 \times 0.2-1.5 \mathrm{~cm}$. Biji banyak.

\section{Mimosa pigra L.}

Semak, tinggi $1 \mathrm{~m}$. batang berambut, berduri 1-2, terletak di internodes, berhadapan, ujung cokelathitam. Berdaun penumpu, berambut. Daun berseling, bipinnate; Sirip 5-15 pasang; anak daun 18-51 pasang, linear, acute, permukaan atas daun berambut halus, permukaan bawah tidak berambut, 4-11 $\mathrm{mm} \times 1 \mathrm{~mm}$. perbungaan head, panjang 1-3 cm; calyx tidak ada atau sangat kecil,; corolla gamopetalous; stamen sebanyak atau dua kali lebih banyak dari segmen corolla; filament berlepasan. Buah polong oblong-linear $4-8 \mathrm{~cm} \times 1 \mathrm{~cm}$.

\section{Mimosa pudica L.}

Semak merambat. Batang berduri, ujung membengkok, berbulu halus. Daun bipinate, 2,5-6 cm; sirip 1 atau 2 pasang; anak daun 12-25 pasang persirip, melonjong, ujung acute atau subotuse, pangkal membulat atau rompang, 5-15 x 1.2-3 mm, hijau kemerah-merahan; Daun penumpu lanset, panjang $1 \mathrm{~cm}$, Perbungaan bongkol, di ketiak daun, tangkai bunga panjang $1 \mathrm{~cm}$. Bunga bongkol, diameter 0,5-1 cm, tangkai pendek, berambut, merah muda; kelopak kecil; mahkota berbentuk tabung, 1-2 $\mathrm{mm}$, bertaju 4; benang sari 4, berlepasan, ungu. Buah tersusun mengelompok tersusun membulat, tangkai pendek, ca. $2 \mathrm{~mm}$; polong lonjong, tipis, $2-3 \times 1.5-2 \mathrm{~mm}$, hijau; permukaan berambut tajam, ungu.

\section{Desmanthus virgatus (L.) Willd.}

Semak, tinggi $2 \mathrm{~m}$. batang halus, keras, persegiempat. Daun menyirip ganda dua; pinnae (1)2-6 pasang, 1-2.5 $\mathrm{cm}$; anak daun 6-12 pasang perpinna, jorong, pangkal truncate (rumpang), ujung runcing, 5-7 $\times 2 \mathrm{~mm}$; daun penumpu berbentuk jarum. Perbungaan bongkol, diameter $5 \mathrm{~mm}$, di ketiak daun, 4-10 bunga. Bunga biseksual; Calyx tabung, $2.5 \mathrm{~mm}, 5$ taju. Petal 5 , sedikit lanset, $4 \mathrm{~mm}$. stamen 10, berlepasan, $5 \mathrm{~mm}$. bakal buah jorong, bakal biji banyak.

\section{Albizia saman (Jacq.) Merr.}

Pohon, tinggi 5-20 m. Batang keras, kulit batang mengelupas, cokelat. Daun menyirip rangkap, panjang 20-30 cm; pinnae 3-9 pasang; anak daun 3-8 pasang, daun membesar hingga ke ujung sirip, bulat telur terbalik, pangkal tidak simetris, ujung membulat, pinggir rata, permukaan atas hijau gelap, permukaan bawah hijau terang, $5-10 \mathrm{~cm} \times 1.5-2 \mathrm{~cm}$. 


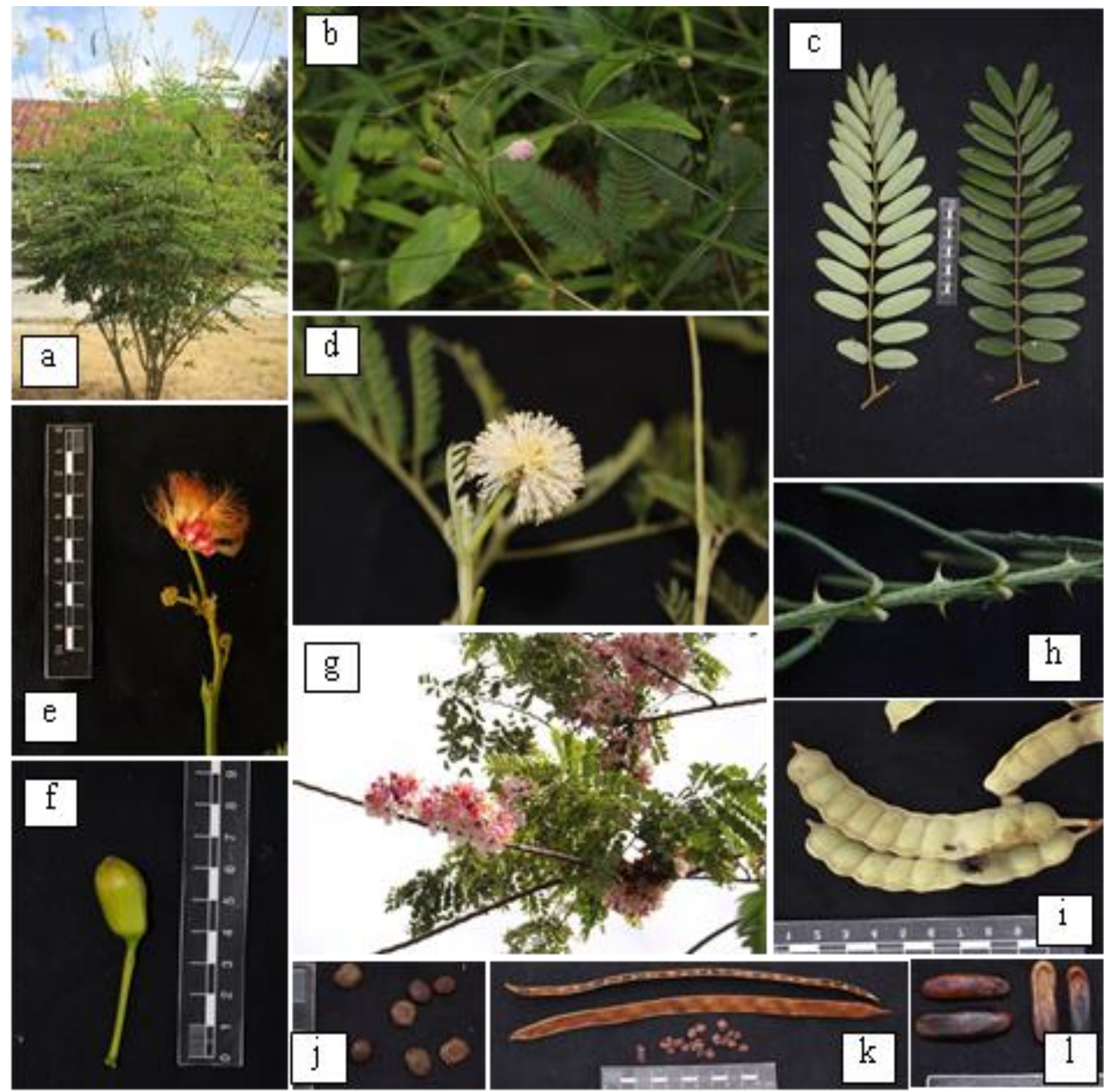

Gambar 2. Caesalpinioideae. a.Pohon kecil Caesalpinia pulcherrima, b. semak Mimosa pudica, c. Daun majemuk dan permukaan daun Senna siamea, d. Bunga bongkol Leucaena leucocephala, e.Perbungaan Albizia saman, f. kelopak tipe valvate Delonix regia, g. Perbungaan Cassia javanica, h. Duri Mimosa pigra, i. Buah Acacia farnesiana, j. Biji A. farnesiana, k. Buah dan biji S. siamea, I. Biji D. regia.

Daun penumpu mudah luruh; pangkal daun membengkak, berlentisel; Perbungaan di ketiak daun, malai, capitulum 1-5, diameter ca. $5-8 \mathrm{~cm}$; tangkai bunga $5-6 \mathrm{~cm}$. Bunga aktinomorfik. Calyx corong, 5-10 $\mathrm{mm}$, hijau kemerahan. Corolla corong, melekat di tengah calyx, merah. Stamen banyak, menyatu di pangkal corolla, pangkal hingga tengah kuning dan ujung merah, panjang 3-6 cm. Putik 1, jarum. Buah polong, melonjong, $10-20 \times 1.2-2 \mathrm{~cm}$. Biji cokelat, elips, ca. $8 \times 5 \mathrm{~mm}$. 


\section{Ucapan Terima Kasih}

Penulis mengucapkan terima kasih kepada UPT. Sumber Daya Hayati, Sulawesi atas izin dan fasilitas selama proses penelitian.

\section{Daftar Pustaka}

Ariati, S. R., Yulistyarini, T., dan Suprapto, A. (2001). Koleksi Polong-polongan Kebun Raya Purwodadi. Seri Koleksi Kebun Raya-LIPI.Vol.III No I. Pasuruan: Kebun Raya Purwodadi-LIPI.

Backer, C.A., and van Den Brink, B, Jr. (1963). Flora of Java 1. Groningen (NL): NVP Noordhoff.

Hou, D., Larse, K., and Larsen, S. S. (1996). Flora Malesianaser. $\quad 1$ : Caesalpiniaceae (Leguminosae-Caesalpinioideae). (pp. 409-730). Leiden: National Herbarium of the Netherlands.12(2).

[ISSG] Invasive Species Specialist Group. 2005. Global Invasive Species. database: http://www.issg.org/database.

[LPWG] Legume Phylogeny Working Group. (2017). A new subfamily classification of the Leguminosae based on a taxonomically comprehensive phylogeny. Taxon, 66(1): 44-77.

Lewis, G. P. (2005). Legumes of the world. Richmond, U.K: Royal Botanic Gardens, Kew.

Nielsen, I. C. (1992). Flora Malesiana ser. 1: Mimosaceae (Leguminosae- Mimosoideae). (pp 1-226). Leiden : National Herbarium of the Netherlands.

Rugayah, Retnowati A, Windadri. F.I, and Hidayat A. (2004). Pengumpulan Data Taksonomi. Di dalam: Rugayah, Widjaja EA, Praptiwi, editor. Pedoman Pengumpulan Data Keanekaragaman Flora. Bogor (ID): Puslit-LIPI.

Simpson, M. G. (2010). Plant systematics. California: Elsevier Academic Press.

van Steenis C.G.G.J. (2006). Flora Pengunungan Jawa. Kartawinata JA, penerjemah. Bogor (ID): Pusat Penelitian Biologi-LIPI. Terjemahan dari: The Mountain Flora Of Java.

Webber E. (2003). Invasive Plant Species of the World : A Refererence Guide to Environmental Weeds. Cambridge: CABI Publishing. 